\title{
COMPARISON OF EFFICACY OF DIODE LASER AND GRAPE SEEDS EXTRACT AS CAVITY DISINFECTANTS IN PRIMARY TEETH- AN IN VITRO STUDY
}

\author{
Mai Hassaballah", Reham Abou El Fadl ${ }^{* *}$ Dalia Sherief $^{* * *}$ and Amr Abdelaziz ${ }^{* * * *}$
}

\begin{abstract}
Purpose: Cavity disinfection is an essential procedure for success of Atraumatic restorative treatment. This study was designed to test the efficacy of diode laser and grape seeds extract as primary teeth cavity disinfectants.

Methods: A total of 96 sound primary molars were divided into two groups according to the test performed $(n=48)$; antimicrobial effect/ shear bond strength. Each group was subdivided into four subgroups according to cavity disinfectants: $(n=12)$; group1: Control (no treatment), group 2: $2 \%$ chlorhexidine gluconates (CHX), group 3: diode laser, group 4: 5\%w/v grape seed extract (GSE). Occlusal cavities were inoculated with the Streptococcus mutans (S.mutans) suspension and incubated under aerobic conditions. Dentine chips were collected and S.mutans colony forming units were counted. For shear bond strength, cylindrical glass ionomer specimens were bonded to dentine surface then loaded at tooth-restoration interface till debonding.
\end{abstract}

Results: Diode laser exhibited the highest antibacterial effect. No difference was detected in mean values of shear bond strength in diode laser (5.88 \pm 1.28$)$ and GSE $(3.47 \pm 1.55)$ groups when compared to the negative control group $(4.97 \pm 1.80)$.

Conclusion: Diode laser system is preferred over GSE and CHX as a potent cavity disinfectant for primary teeth. GSE can be used as a natural alternative for CHX

KEY WORDS: Cavity disinfection, primary teeth, diode laser system, grape seeds extract

\section{INTRODUCTION}

Dental caries is one of the most common preventable childhood diseases which occur due to a dynamic process of demineralization and remineralization of enamel and dentin. This process stems from the production of organic acids by cariogenic microorganisms. ${ }^{[1,2]}$ One common form of tooth decay is early childhood caries (ECC) which

\footnotetext{
* Assistant Lecturer, Department of Pediatric Dentistry, Faculty of Dentistry, 6 October University, Egypt

** Associate Professor, Pediatric Dentistry and Dental Public Health Faculty of Dentistry, Ain Shams University, Cairo, Egypt *** Lecturer, Department of Biomaterials, Faculty of Dentistry, Ain Shams University, Cairo, Egypt **** Professor, Pediatric Dentistry and Dental Public Health, Faculty of Dentistry, Ain Shams University, Cairo, Egypt
} 
is characterized by the occurrence of one or more decayed/missed teeth due to caries, or filled tooth surfaces in any of the primary teeth in a child under the age of six. This happens when tooth-adherent bacteria are transmitted vertically from the mother or caregiver to the child or horizontally from one child to another while kissing, sharing toothbrushes or drinking from the same cup or bottle. ${ }^{[3]}$

The new era of minimum invasive dentistry which is also called micro-dentistry, aimed to keep teeth in function as much as possible. It advocates for maximum conservation of the remaining tooth structure rather than the old concept of G.V. Black. Atraumatic Restorative Treatment (ART) is a minimally invasive approach which halts the development of caries and prevents its further progression. The technique involves removal of the outer layer of infected decomposed decay using a hand instrument, leaving the inner affected demineralized part of the lesion to avoid pulpal exposure, and hence preserve its vitality. ${ }^{[4]}$

Any bacteria left in the prepared cavity under a well-sealed restoration will be deprived from the source of nutrition required for acid production; thereupon, no further dentin demineralization would take place. ${ }^{[5,6]}$ Some studies, however, have raised concerns that bacteria left in the cavity might still multiply leading to secondary caries development especially in multi-surface restorations. ${ }^{[7,8]}$ It has, thus, been strongly recommended to disinfect the cavity before the application of any restoration. Many products have been used for this purpose including, but not limited to, chlorhexidine gluconate (CHX) and sodium hypochlorite. Though CHX has been considered as the "gold standard" of oral antiseptics however ${ }^{[9]}$, it is widely known that it may cause staining and discoloration to a tooth surface and might also have some cytotoxic effects against human fibroblasts through inhibition of protein synthesis. ${ }^{[10]}$

Diode laser is known to be effective in many dental procedures; it aids in coagulation, so it has a role in soft tissue surgery as well as disinfection of periodontal pockets. ${ }^{[11]}$ It plays an important role in caries prevention as it increases the resistance of enamel surface to acids. ${ }^{[12]}$ Diode lasers were also found to exhibit a bactericidal effect against enterococcus feacalis, and were, thus, used in decontamination/disinfection of root canals. ${ }^{[13]}$ For similar purpose, many natural products such as propolis, miswak, and aloe vera were also tested for their antimicrobial effects. ${ }^{[14,15]}$ Grape Seed extract (GSE) is one of the natural products that was found to be rich in polyphenolic compounds such as epicatechin and proanthocyanidins which are known for their antibacterial effect. ${ }^{[16]}$

This study was, thus, conducted to compare the antibacterial effects of diode laser and GSE to $\mathrm{CHX}$ and investigate the effects of using them as cavity disinfectants on bond strength of glass ionomer restorations to dentine in primary teeth. In the present work, the null hypotheses tested were (1) no difference existed in antibacterial activity against Streptococcus mutans (S.mutans) between diode laser, GSE and CHX and (2) the tested cavity disinfectants had no effect on shear bond strength of glass ionomer to dentin in primary teeth.

\section{MATERIALS AND METHODS}

\section{Experimental design and sample size}

This in vitro study was carried out in the Biomaterials department and Laser center at Faculty of Dentistry over a period of three months from May 2019 to August 2019.

A power analysis was designed to have adequate power to apply a two-sided statistical test of the research hypotheses (null hypotheses) that there was no difference between tested materials regarding both shear bond strength and anti-bacterial effect. According to the results of a conducted pilot study, in which the effect size was calculated to be $(\mathrm{f}=0.59)$, and by assuming an alpha $(\alpha)$ level of $0.05(5 \%)$ and a Beta $(\beta)$ level of $0.20(20 \%)$ i.e. power $=80 \%$; the predicted sample size (n) was a total of (36) cases 
i.e. (9) for each group. Sample size was increased to be (48) i.e. (12) for each group measured variable to compensate for any margin of error. Sample size calculation was performed using $\mathrm{G}^{*}$ Power version 3.1.9.2*.

\section{Sample grouping}

A total of ninety-six sound mandibular or maxillary first or second primary molars which either exfoliated due to physiologic reasons or were indicated for extraction due to root resorption were collected from anonymous patients attending the outpatient clinic in Pediatric Dentistry and Dental Public Health Department, Faculty of Dentistry, Ain Shams University. All patients' guardians were informed that the teeth will be used for research purpose. Carious or fractured teeth and those with developmental anomalies were excluded. The molars were divided into two groups according to the performed test $(n=48)$. Each group of teeth were further subdivided to one of four groups (each group $\mathrm{n}=12$ ) based on cavity disinfection.

\section{Evaluation of antibacterial effect}

\section{Samples preparation}

Roots of the collected primary molars were removed under running water then teeth were cleansed and autoclaved for $15 \mathrm{~min}$. at $121^{\circ} \mathrm{C}$. A uniform cavity ( $2 \mathrm{~mm}$ in width, $1 \mathrm{~mm}$ in depth) was prepared on the occlusal surface of each tooth using a sterile round bur size 4 at low speed under water coolant. S.mutans ATCC 25175 was placed on mitis salivarius agar; incubated aerobically at $37^{\circ} \mathrm{C}$ for $24-$ 48 hours. ${ }^{[17]}$ Three to five well isolated colonies of the same morphological type were selected from the mitis salivarius agar plate, cultured and transferred with a sterile loop into a tube containing $5 \mathrm{~mL}$ of Brain Heart Infusion (BHI) broth that was incubated at $37^{\circ} \mathrm{C}$ for 24 hours. The turbidity of the broth culture was adjusted to 0.5 McFarland standards, containing $1.5 \times 10^{8}$ bacterial cells per $\mathrm{ml}$. Each cavity was inoculated with the bacterial suspension and incubated for another 24 hours.${ }^{[17]}$ Each of the primary molars with prepared cavities was, then, randomly allocated to one of the following four groups (table 1):

TABLE (1) Materials/devices used in the study, their manufacturers and techniques of application.

\begin{tabular}{|l|l|l|l|}
\hline & Material/device & Manufacturer & Application technique \\
\hline Group 1 & Control & - & Rinsing without treatment \\
\hline Group 2 & $\begin{array}{l}\text { Commercially available 2\% } \\
\text { CHX solution in syringe form }\end{array}$ & $\begin{array}{l}\text { Consepsis }{ }^{\circledR}, \quad \text { Ultra dent } \\
\text { products, Inc., USA. }\end{array}$ & $\begin{array}{l}\text { CHX applied to the prepared cavity by micro-brush } \\
\text { tip for 20s then dried for 10s. }{ }^{[18]}\end{array}$ \\
\hline Group 3 & Diode Laser & $\begin{array}{l}\text { USA } \\
\text { the diode laser tip was applied perpendicularly to } \\
\text { the prepared cavity (contact mode) to ensure that all } \\
\text { testing areas were irradiated equally for } 5 \text { cycles }(15 \\
\text { seconds each) with a pause of } 15 \text { seconds between } \\
\text { one cycle and the other. }{ }^{[19]}\end{array}$ \\
\hline Group 4 & $\begin{array}{l}\text { Grape seeds aquatic extract } \\
(5 \% \text { w/v) }\end{array}$ & $\begin{array}{l}\text { GSE was freshly prepared where 5gms of the extract } \\
\text { powder were mixed in 100ml of distilled water and } \\
\text { stirred, then the mixture was filtered. } \\
\text { was] } \text { The extract } \\
\text { micro brush tip for 1 min then washed away. }{ }^{[21]}\end{array}$ \\
\hline
\end{tabular}

* Faul Franz, et al. "G* Power 3: A flexible statistical power analysis program for the social, behavioral, and biomedical sciences.” Behavior research methods 39.2 (2007): 175-191. 


\section{Experimental procedures}

A standardized amount of dentin chips $(20 \mathrm{mg}$ ) was collected from the cavity walls of each tooth using sterile, No 4. Round bur mounted on a lowspeed contra-angle hand-piece. For each cavity, a new bur was used to avoid over-heating while cutting. The collected chips were then transferred into a sterile Eppendorf tube containing $1 \mathrm{ml}$ of sterile phosphate buffered saline using paper point. After serial dilutions were done, ten microliters of each dilution were dispensed over a petri-dish of Mitis-Salivarius agar. The number of S.mutans colony forming units was then counted.

\section{Shear bond strength test}

\section{Samples preparation}

Each of the 48 primary molars was securely embedded in standardized cylindrical teflon molds. The buccal, lingual or palatal surface of each tooth was flattened by using a diamond stone with tapered end at low speed till the yellow dentin was reached. ${ }^{[22]}$ Prepared teeth were randomly assigned to one of the four groups according to the cavity disinfectant used. Dentin conditioner was applied to the dentin surface for 20 seconds by using cotton pellet, then, washed off gently with distilled water and dried by air syringe. ${ }^{[22]}$ Fuji IX (FJ, GC Corporation, Japan) glass ionomer was mixed according to manufacturer's instructions and applied into a special cylindrical plastic tube of length about $3 \mathrm{~mm}$ with internal diameter of $3 \mathrm{~mm}$ placed on top of the prepared surface of each tooth.

\section{Experimental procedures}

Each specimen was loaded in a universal testing machine (Lloyed instrument LR5K series-UK). Force was applied at tooth-restoration interface by using chisel knife edge blade until the glass ionomer restoration was dislodged from the dentin surface. The force, in Newton $(\mathrm{N})$, required to displace the GIC restoration was recorded and the bond strength was calculated by dividing the shear force $(\mathrm{N})$ by the bonded area. ${ }^{[23]}$

\section{Statistical analysis}

Numerical data was explored for normality using Kolmogorov-Smirnov and Shapiro-Wilk tests. Bacterial count data showed non-parametric distribution and were positively skewed so log transformation was made to achieve normality. One-way ANOVA was used to examine differences between groups and this was followed by multiple pairwise comparisons utilizing Tukey's post hoc test when the ANOVA test was found significant. Significance was set at $p<0.05$. Statistical analysis was performed with IBM ${ }^{\circledR}$ SPSS $($ Statistics Version 25 for Windows.

\section{RESULTS}

\section{Antibacterial effects (CFU/ml)}

Table 2. shows the mean and standard deviation values of bacterial count of $S$. mutans in the four groups. A significant reduction in CFUs was detected in diode laser group when compared to the other three groups $(\mathrm{p}<0.001)$. However, there was no statistically significant difference between the antibacterial effects of GSE and CHX. This was also observed in Mitis-Salivarius agar petri-dishes (fig.1, fig.2, fig.3)

TABLE (2) Mean \pm standard deviation (SD) of log bacterial count $(\mathrm{CFU} / \mathrm{ml})$

\begin{tabular}{|c|c|c|c|}
\hline \multirow{2}{*}{$\begin{array}{c}\text { Log bacterial } \\
\text { count }\end{array}$} & \multirow{2}{*}{ mean \pm SD } & $\begin{array}{c}\text { 95\% CI } \\
\text { bound }\end{array}$ & $\begin{array}{c}\text { Upper } \\
\text { bound }\end{array}$ \\
\cline { 3 - 4 } & & 5.53 & 6.72 \\
\hline $\mathbf{2 \%}$ CHE & $6.12 \pm 0.93^{\mathrm{B}}$ & 2.87 & 6.44 \\
\hline Diode Laser & $1.00 \pm 0.70^{\mathrm{C}}$ & 0.55 & 1.45 \\
\hline Negative control & $9.51 \pm 0.03^{\mathrm{A}}$ & 9.50 & 9.53 \\
\hline P-value & \multicolumn{3}{|c}{$<0.001^{\mathrm{B}}$} \\
\hline
\end{tabular}

Different superscript letters within the same vertical column indicate a statistically significant difference *; significant $(p \leq 0.05) n s ;$ non-significant $(p>0.05)$ 


\section{Shear bond strength}

The mean values of the bond strength in the four groups and their standard deviations are summarized in Table 3. Among all groups, samples treated with diode laser showed the highest shear bond strength $(5.88 \pm 1.28)$ to dentine. CHX showed the least bond strength which was significantly lower than the control group (without cavity disinfection) $(\mathrm{P}<0.001)$.

TABLE (3) Mean \pm standard deviation (SD) of shear bond strength $(\mathrm{MPa})$

\begin{tabular}{|c|c|c|c|}
\hline \multirow{2}{*}{$\begin{array}{c}\text { Shear bond } \\
\text { strength }\end{array}$} & \multirow{2}{*}{ Mean \pm SD } & $\begin{array}{c}|c| \\
\text { Lower } \\
\text { bound }\end{array}$ & $\begin{array}{c}\text { Upper } \\
\text { bound }\end{array}$ \\
\hline Diode Laser & $5.88 \pm 1.2^{8} \mathrm{~A}$ & 5.07 & 6.7 \\
\hline Negative control & $4.97 \pm 1.80^{\mathrm{AB}}$ & 3.7 & 6.25 \\
\hline GSE & $3.47 \pm 1.55^{\mathrm{BC}}$ & 2.48 & 4.46 \\
\hline 2\% CHX & $3.06 \pm 1.17^{\mathrm{C}}$ & 2.32 & 3.87 \\
\hline P-value & & $<0.001^{*}$ \\
\hline
\end{tabular}

*Different superscript letters within the same vertical column indicate a statistically significant difference; significant ( $p \leq 0.05) n s ;$ non-significant $(p>0.05)$

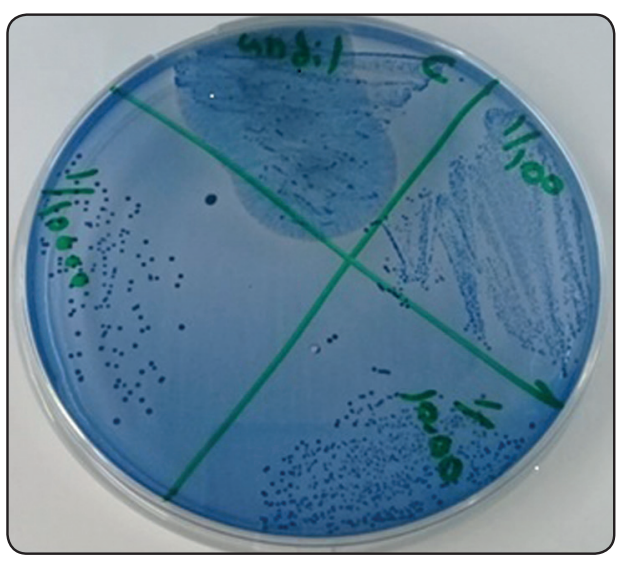

Fig. (1) Mitis salivarius agar prior to disinfection

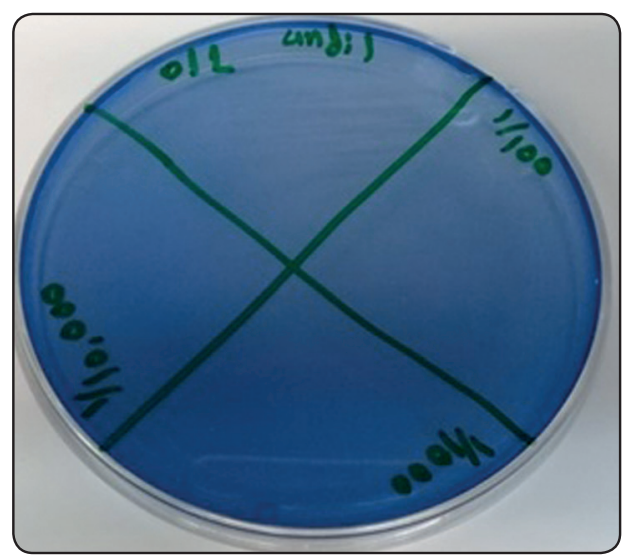

Fig. (2) Mitis salivarius agar after cavity disinfection with diode laser

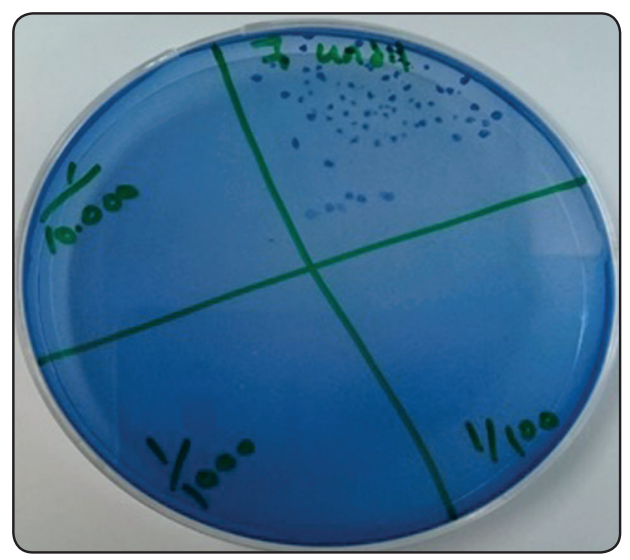

Fig. (3): Mitis salivarius agar after cavity disinfection with GSE

\section{DISCUSSION}

ART is a restorative concept which advocates for maximum conservation of the tooth structure while causing minimal discomfort to the patient and has been used both in dental settings and in the field. The approach is, usually, widely accepted by children and adults as it rarely needs local anesthesia, thus suitable for uncooperative patients ${ }^{[24]}$. Nevertheless, it has been proven that, in this technique, cariogenic bacteria can easily penetrate dentinal tubules and multiply owing to their very small size. This, in turn, might lead to development of recurrent caries, a common disadvantage of ART and hence subsequent failure of restoration. ${ }^{[7,8]}$ Thus, cavity disinfection has been 
strongly recommended for eliminating cariogenic bacteria left under the restoration which in turn reduces the potentials for development of recurrent lesions and enhance the survival rate of ART restorations. ${ }^{[14,18]}$ Accordingly, the present study was conducted to test the viability of using diode laser system and GSE as cavity disinfectants under glass ionomer restoration in primary teeth.

Glass ionomer Fuji IX was used in the current study since high viscosity glass ionomer cements are the restorative materials of choice for ART technique due to ease of use since no specific equipment is required for mixing and application. Added to that, it binds chemically to both enamel and dentine and is characterized by good sealing properties, and minimal sensitivity in saliva ${ }^{[25]}$.

Diode laser system has its widespread applications in endodontic treatment for the purpose of decontamination owing to its the ability to eliminate any remaining viable bacteria and remove smear layer as well with great efficacy ${ }^{[26]}$. This antimicrobial effect is based on a rise in temperature which damages the bacterial cells; hence described as photo-thermal effect. ${ }^{[27]}$ Moreover, it is worth mentioning that using different laser systems for direct pulp capping treatment in various studies brought about good clinical outcomes ${ }^{[28]}$ and diode laser system per se has an advantage of stimulating better healing of pulpal tissues ${ }^{[29]}$. Because the time of exposure has a significant influence on the antimicrobial properties of diode laser, in the current study, cavity irradiation was repeated five times (15 secs. each) to ensure that bacteria hidden in deeper layers of dentine is reached ${ }^{[19]}$. In addition, the final output power setting was adjusted at $1.3 \mathrm{~W}$ which lies within the safe limit proposed by Gutknecht et al. ${ }^{[30]}$ The hand-piece was directed perpendicularly to the cavity in contact mode to ensure that the tested areas were scanned and irradiated equally at the same time as recommended by Maenosono et al. ${ }^{[31]}$
GSE, on the other hand, being a natural product, is safe to be used even in high concentrations and is known to exhibit various forms of antimicrobial activity ${ }^{[16,32]}$.Though the antibacterial capacity of the alcoholic GSE extract could be higher when compared to the aquatic extract, yet, in our study, the aquatic extract was used to avoid any overlap between the antibacterial effect of methanol and that of GSE. On the other hand, 2\% CHX was selected as a positive control, as it has been widely recognized over decades as the gold standard antimicrobial agent owing to its effect against broad spectrum of gram-positive and gram-negative bacteria as well as facultative and anaerobic microorganisms.

In the current study, considering that diode laser was found to exhibit significantly higher bactericidal effect against S.mutans when compared to the two other disinfectants (fig.2), the first null hypothesis was rejected. After irradiation with the laser system no bacteria was left and this goes in line with the study done by Mohan PU et al. ${ }^{[18]}$ who reported that diode laser could eliminate $99.9 \%$ of S.mutans present in a cavity and related that to its thermal and photo-disruptive effects which can cause a lethal damage to the integrity of the bacterial cell wall with possible denaturation of the proteins. According to, Lee et al., ${ }^{[26]}$ and Kouchi et al., ${ }^{[33]}$ S.mutans can reach a depth of $1150 \mu \mathrm{m}$ of dentinal tubules and whereas the antibacterial efficacy of $2 \% \mathrm{CHX}$ is limited to $130 \mu \mathrm{m}$ in depth of dentinal tubules where only $54 \%$ of the cariogenic bacteria in dentine can be reached, diode laser irradiations can penetrate the dentinal tubules up to $1000 \mu \mathrm{m}$ in depth and thereby can eradicate $97 \%$ of the bacterial load. ${ }^{[34]}$

On the other hand, it is well-known that GSE contains bioflavonoids, epicatechin compounds and proanthocyanidins which have good antimicrobial potentials. Despite that, the antibacterial effect of the aquatic extract of grape seeds wasn't as strong as diode laser (fig.3). A plausible explanation, for this limited effect against S.mutans is its poor dissolution in water ${ }^{[35]}$ when compared to its dissolution rate in 
methanol. This goes in agreement with Swadas $M$ et al., ${ }^{[16]}$ results who indicated that though GSE has an inhibitory effect against $S$.mutans yet it was even less effective than CHX.

In the present study, it was also revealed that whereas neither diode laser system nor GSE had an adverse effect on the bond strength of GIC to dentin in primary molars, there was a significant reduction with CHX hence the second null hypothesis was also rejected. Diode lasers are known to be highly efficacious in removing the smear layer thus allowing for adequate adhesion of the restorative material to the tooth structure ${ }^{[36]}$.In addition, owing to the high heat generated when teeth are treated with diode laser, evaporation of any water or solvent content in dentin might have allowed more penetration of the adhesive material ${ }^{[31]}$. This might explain the slight increase in the bond strength of the restoration after irradiation with diode laser system as revealed in this study finding.

Though on using GSE for cavity disinfection in primary teeth the shear bond strength between GIC and dentine slightly decreased yet this change was insignificant. In various studies it was revealed that proanthocyanidin, the main phenolic compound in GSE ${ }^{[37]}$, tends to enhance the bond strength of GSE to treated dentin surfaces due to its role as a collagen cross-linking agent ${ }^{[38,39]}$. However, such cross-linking effect of GSE is known to be time and concentration dependent ${ }^{[40]}$. Accordingly, in the current study, it is possible that either the concentration or the time of application of GSE or even both were not sufficient enough to enhance adequate bond strength to dentin.

On the other hand, a significant reduction of bond strength of GIC to dentine in primary teeth was encountered after treatment with $\mathrm{CHX}$. This could be attributed to the cationic properties of $\mathrm{CHX}$ which might have interfered with the conventional GIC setting mechanism which involves the leaching of ions from the glass particles after being attacked by the hydrated protons from the polyacid ${ }^{[41]}$. Such interposition could possibly reduce the mechanical properties of GIC at the bonded surface thereby adversely affecting the bond strength.

Though in-vitro studies can provide valuable information about the characteristics of any materials used in dental field prior to being tested in humans yet one disadvantage is that in-vitro research can't mimic the real dynamic environment of oral cavity which usually challenges the durability of different restorations. Acknowledging the effectiveness of both tested material in reducing S.mutans load and since ART approach proved useful as well in delivering dental treatment to adults, testing the effects of using both diode laser and GSE for cavity disinfection in permanent teeth on the basic properties of glass ionomer is highly recommended. It is also noteworthy that in all groups the tested specimens were not subjected to storage over time prior to measuring shear bond strength. Thus, further research needs to be conducted to assess and compare the effects of using both diode laser and GSE for cavity disinfection on bond strength of glass ionomer to dentine after storage / aging for long duration (3-6 months). Moreover, it is necessary to consider testing the effects of other combinations of wavelengths of diode lasers with different power settings and irradiation exposure time that would generate less heat without jeopardizing its antibacterial effects.

\section{CONCLUSIONS}

Within the limitations of this study it could be concluded that:

1. Diode laser system and the aquatic extract of grape seeds could be used for cavity disinfection without adversely affecting the bond strength of glass ionomer restorations to dentine in primary teeth.

2. Diode laser system proved to be the most effective against S.mutans.

3. Aquatic GSE exhibited an antibacterial effect comparable to that of $\mathrm{CHX}$ and thus could be used as a safe alternative for it. 


\section{Conflict of interest:}

The authors declare that they have no conflict of interest

\section{REFERENCES}

1. Robert HS, Amid II, Nigel BP. Dental caries. Lancet. 2007; 369(9562):51-59.

2. Fejerskov O, Nyvad P, Kidd EAM. Pathology of Dental caries. In: Frejerskov O, Kidd EAM, (eds). Dental caries: the disease and its clinical management. $2^{\text {nd }}$ ed. Oxford: Blackwell Monksgaard. 2008. p. 20-48.

3. American Academy of Pediatric Dentistry. Policy on Early Childhood Caries (ECC): Classifications, consequences and preventive strategies. Available at: http://www.aapd.org/ media/Policies_Guidelines/P_ECC Classification1.2019.

4. Frencken JE, van Amerongen WE. The Atraumatic Restorative Treatment approach. In Fejerskov O, Kidd EA, (eds). Dental caries: The disease and its clinical management. $2^{\text {nd }}$ ed. Oxford, Blackwell Munksgaard. 2008. p. 427-442.

5. Franzon R, Guimarães LF, Magalhães CE, Haas AN, Araujo FB. Outcomes of one step incomplete and complete excavation in primary teeth: A 24 month randomized controlled trial. Caries Res. 2014; 48(5):376-383.

6. De Amorim RG, Frencken JE, Raggio DP, Chen X, Hu X, Leal SC . Survival percentages of atraumatic restorative treatment (ART) restorations and sealants in posterior teeth: an updated systematic review and meta-analysis. Clin Oral Investig .2018;22(8):2703-2725.

7. Toi CS, Bönecker M, Cleaton-Jones PE. Mutans streptococci strains prevalence before and after cavity preparation during Atraumatic Restorative Treatment. Oral Microbiol. Immunol. 2003; 18(3):160-4.

8. Raggio DP, Tedesco TK, Calvo AF, Braga MM. Do glass ionomer cements prevent caries lesions in margins of restorations in primary teeth? A systematic review and meta-analysis. J Am. Dent. Assoc. 2016; 147(3):177-85.

9. Matthijs S, Adriaens PA. Chlorhexidine varnishes: a review. J Clin. Periodontol. 2002; 29(1):1-8.

10. Liu JX, Werner J, Kirsch, Zuckerman JD, Virk MS. Cytotoxicity evaluation of chlorhexidine gluconate on human fibroblasts, myoblasts, and osteoblasts. J Bone Jt. Infect. 2018; 3(4):165-172.
11. Olivi G, Olivi M. Physics of lasers. Lasers in Restorative Dentistry: A Practical Guide.1st ed., Springer-Verlag Berlin Heidelberg. 2015. p.39-50.

12. Vitale MC, Zaffe D, Botticell AR, Caprioglio C. Diode laser irradiation and fluoride uptake in human teeth. Eur. Arch. Paediatr. Dent. 2011; 12(2): 90-92.

13. Thomas S, Asokan S, John B, Priya G, Kumar S. Comparison of antimicrobial efficacy of diode laser, Triphala, and Sodium Hypochlorite in Primary Root Canals: A Randomized Controlled Trial. Int. J. Clin. Pediatr. Dent.2017;10(1):14-17.

14. Prabhakar AR, Karuna YM, Yavagal C, Deepak BM. Cavity disinfection in minimally invasive dentistry -comparative evaluation of aloe vera and propolis: A randomized clinical trial. Contemp. Clin. Dent. 2015; 6(1):24-31.

15. Salama F, Balto H, Al-Yahya F, Al-Mofareh S. The effect of cavity disinfectants on microleakage of composite restorations in primary teeth. Eur J. Paediat. Dent. 2015; 16(4):295-300.

16. Swadas M, Dave B, Vyas SM, Shah N. Evaluation and Comparison of the Antibacterial Activity against Streptococcus mutans of Grape Seed Extract at Different Concentrations with Chlorhexidine Gluconate: An in vitro Study. Int..J. Clin. Pediatr. Dent.2016; 9(3):181-185.

17. Kim BR, Oh MH, Shin DH. Effect of cavity disinfectants on antibacterial activity and micro-tensile bond strength in class I cavity. Dent. Mater. J. 2017; 36(3):368-373.

18. Mohan PU, Uloopi KS, Vinay C, Rao RC. In vivo comparison of cavity disinfection efficacy with APF gel, propolis, diode laser and $2 \%$ chlorhexidine in primary teeth. Contemp. Clin. Dent. 2016; 7(1):45-50.

19. Katalinić I, Budimir A, Bošnjak Z, Jakovljević S, Anić I. The photo-activated and photo-thermal effect of the $445 / 970 \mathrm{~nm}$ diode laser on the mixed biofilm inside root canals of human teeth in vitro: A pilot study. Photodiagnosis Photodyn. Ther. 2019; 26:277-283.

20. Abraham S, Ghonmode WN, Saujanya KP, Jaju N, Tambe $\mathrm{VH}$, Yawalikar PP. Effect of grape seed extract on bond strength of bleached enamel using fifth and seventh generation bonding agents. J. Int. Oral. Health.2013; 5(6):101-107.

21. Yingxin XU, Jianfeng ZHOU and Jianguo TAN. Use of grape seed extract for improving the shear bond strength of total-etching adhesive to bleached enamel. Dent. Mater.J.2018; 37(2): 325-331. 
22. Somani R, Jaidka S, Singh DJ, Sibal GK. Comparative Evaluation of Shear Bond Strength of Various Glass Ionomer Cements to Dentin of Primary Teeth: An in vitro Study. Int.J. Clin. Pediatr. Dent. 2016; 9(3):192-196.

23. Awliya WY, Akpata ES. Effect of fluorosis on shear bond strength of glass ionomer-based restorative materials to dentin. J Prosthet. Dent. 1999; 81(3):290-4.

24. Kateeb ET, Warren J, Gaeth G, Damiano P, Momany E, Kanellis MJ, et al. The willingness of US pediatric dentists to use atraumatic restorative treatment (ART) with their patients: a conjoint analysis. J. Public Health Dent. 2014; 74(3):234-40.

25. Yip HK, Smales RJ, Ngo HC, Tay FR, Chu FC. Selection of restorative materials for the atraumatic restorative treatment (ART) approach: a review. Special Care in Dentistry 2001; 21(6):216-21.

26. Lee BS, Lin YW, Chia JS. Bactericidal Effects of diode laser on streptococcus mutans after irradiation through different thickness of dentin. Lasers Surg. Med. 2006; 38(1): 62-69.

27. Pirnat S, Lukac M, Ihan A. Study of the direct bactericidal effect of Nd:YAG and diode laser parameters used in endodontics on pigmented and non-pigmented bacteria. Lasers Med. Sci. 2011; 26:755-761.

28. Deng Y, Zhu X, Zheng D, Yan P, Jiang H. Laser use in direct pulp capping: : A meta-analysis. J Am Dent Assoc. 2016; 147(12):935-942.

29. Hilton TJ. Keys to clinical success with pulp capping: a review of the literature. Oper Dent. 2009; 34(5):615-25.

30. Gutknecht N, Franzen R, Meister J, Vanweersch L, Mir M. Temperature evolution on human teeth root surface after diode laser assisted endodontic treatment. Lasers Med Sci. 2005; 20(2):99-103.

31. Maenosono RM, BimJúnior O, Duarte MAH, Palma-Dibb RG, Wang L, Ishikiriama SK. Diode laser irradiation increases micro-tensile bond strength of dentin, Original Research Oper.Dent.2015;29(1):1-5.

32. Ghonmode WN, Balsaraf OD, Tambe VH, Saujanya KP,
Patil AK, Kakde DD. Comparison of the antibacterial efficiency of neem leaf extracts, grape seed extracts and 3\% sodium hypochlorite against E. feacalis - An in vitro study. J. Int. Oral Health. 2013; 5(6):61-6.

33. Kouchi Y, Ninomiya J, Yasuda H, Fukui K, Moriyama T, Okamoto H Location of Streptococcus mutans in the dentinal tubules of open infected root canals. J Dent Res.1980; 59(12): 2038-46.

34. Schoop U, Kluger W, Dervisbegovic S, Goharkhay K, Wernisch J, Georgopoulos A, et al. Innovative wavelengths in endodontic treatment. Lasers Surg. Med. 2006; 38(6):624-30.

35. Furiga A, Lonvaud-Funel A and Badet C (2009) In vitro study of antioxidant capacity and antibacterial activity on oral anaerobes of a grape seed extract. Food Chem.2009;113:1037-1040.

36. Wang X, Sun Y, Kimura Y, Kinoshita J, Ishizaki NT, Matsumoto K. Effects of diode laser irradiation on smear layer removal from the root canal walls and apical leakage after obturation. Photomed. Laser Surg. 2005; 23(6): 575-581.

37. Shi J, Yu J, Pohorly JE, Kakuda Y. Polyphenolics in grape seeds-biochemistry and functionality. J Med. Food 2003; 6(4):291-9.

38. Islam S, Nassar M, Yiu C, Otsuki M, Tagami J. Effect of natural cross-linkers incorporation in a self-etching primer on dentine bond strength. J Dent. 2012; 40(12):1052-9.

39. Epasinghe DJ, Yiu CK, Burrow MF, Tay FR, King NM. Effect of proanthocyanidin incorporation into dental adhesive resin on resin-dentine bond strength. J Dent. 2012; 40(3):173-80.

40. Fang M, Liu R, Xiao Y, Li F, Wang D, Hou R, Chen J. Biomodification to dentin by a natural cross-linker improved the resin-dentin bonds. J Dent. 2012; 40(6): 458-66.

41. Takahashi Y, Imazato S, Kaneshiro AV, Ebisu S, Frencken JE, Tay FR. Antibacterial effects and physical properties of glass-ionomer cements containing chlorhexidine for the ART approach. Dent Mater. 2006; 22(7):647-52. 